\title{
Ambient ozone concentrations induce airway hyperresponsiveness in some rat strains
}

\author{
P. Depuydt, G.F. Joos, R.A. Pauwels
}

\begin{abstract}
Ambient ozone concentrations induce airway hyperresponsiveness in some rat strains. $P$. Depuydt, G.F. Joos, R.A. Pauwels. (C)ERS Journals Ltd 1999.

ABSTRACT: Ozone is known to induce airway hyperresponsiveness (AHR) in humans and animals. Previous studies in animals used high exposure levels and reported inconsistent results. The aim of this study was to investigate the effect of a single lowlevel ozone exposure on different inbred rat strains.

Nine rat strains were exposed to 0.05 parts per million (ppm) for $4 \mathrm{~h}$ and airway responsiveness to intravenous 5-hydroxytryptamine (HT) examined. Bronchoalveolar lavage fluid (BALF) was examined for the presence of inflammatory cells and markers.
\end{abstract}

Lewis, BDII and Long-Evans rats developed AHR 90 min after ozone exposure, whereas Wistar, Sprague-Dawley, Fisher 344, Brown-Norway, BDE and DA rats did not. Baseline airway responsiveness to 5-HT differed significantly between rat strains, but did not correlate with the presence or absence of ozone-induced AHR. No inflammatory cell influx was found in BALF of any rat strain. In Long-Evans rats, AHR lasted up to $12 \mathrm{~h}$ after ozone exposure despite the absence of an inflammatory cell influx or increase in lactate dehydrogenase, alkaline phosphatase or total protein in BALF.

In conclusion, exposure to an ambient concentration of ozone induced airway hyperresponsiveness without airway inflammation in some highly inbred rat strains. Genetic factors are likely to account for the observed variability in sensitivity of the airways to ozone.

Eur Respir J 1999; 14: 125-131.

Ozone is a ubiquitous air pollutant which is known to cause lung function decrements, bronchial hyperresponsiveness and airway inflammation in humans as well as in different animal species $[1,2]$. Exposure to ozone is known to cause acute deterioration of asthma as reflected by an increase in hospital admissions for asthma attacks, as well as peak flow decrements in asthmatics [1]. Bronchial hyperresponsiveness is also a major feature of human asthma, and the degree of this hyperresponsiveness correlates with the severity of asthma and the treatment required to control symptoms [3]. The induction of bronchial hyperresponsiveness by ozone is therefore one of its important effects on the airway.

Ozone-induced airway hyperresponsiveness has been documented in different animal species, and a large number of studies have been performed to elucidate the mechanisms of this hyperresponsiveness. However, thus far these animal studies have used high ozone concentrations (0.8-2 parts per million ( $\mathrm{ppm})$ ), which are seldom encountered in ambient circumstances, and revealed inconsistent results that could be due to species differences or different exposure levels.

Rats are frequently used in toxicology studies, and ozone is known to cause airway inflammation and epithelial desquamation in rats [4]. However, very few studies addressed the problem of ozone-induced airway hyperresponsiveness in rats, and no information is present about the susceptibility to ozone in different rat strains. An interstrain susceptibility is to be expected, as strain differences were previously observed in several rat models of airway hyperresponsiveness [5].

The aim of this study was to investigate the effect of a single exposure to a low dose of ozone on airway responsiveness and inflammation in different rat strains. In a second experiment, a sensitive and a resistant strain were examined at different time-points after the exposure to ozone, to compare the time-course of bronchial hyperresponsiveness and inflammation. A very low ozone concentration was chosen for exposure: $0.05 \mathrm{ppm}$ for $4 \mathrm{~h}$. This cumulative dose represents an exposure level that can be encountered in ambient circumstances during spring and summer time, even outside high pollution episodes [1].

\section{Materials and methods}

Animals

Male Long-Evans, Sprague-Dawley, Fisher 344, BrownNorway, BDII, BDE, DA, Lewis and Wistar rats were obtained from Harlan CBP (Zeist, the Netherlands). LongEvans, Sprague-Dawley, Fisher 344, Brown-Norway, BDII, BDE and Lewis rats were highly inbred. All rats were specific-pathogen free. Rats were about 6-8 weeks 
old and weighed 200-300 g at the time of testing. All animals were housed in the animal research facility of the University Hospital (Ghent, Belgium) and received food and water ad libitum. Rats were allowed to acclimatize for one week before starting the exposures.

\section{Study design}

Influence of strain of rats on bronchial responsiveness and airway inflammation following ozone exposure. Nine groups of 20 rats from different strains (LongEvans, Sprague-Dawley, Fisher 344, Brown-Norway, BDII, BDE, DA, Lewis and Wistar) were used. From each strain, 10 rats were exposed to ozone $(0.05 \mathrm{ppm})$ and 10 to room air. Airway responsiveness to 5-hydroxytryptamine (HT) was assessed $90 \mathrm{~min}$ after the end of exposure in all rats and bronchoalveolar lavage (BAL) was performed subsequently.

Time course of bronchial responsiveness and airway inflammation following ozone exposure in Long-Evans and Fisher 344 rats. Airway responsiveness to 5-HT and BAL was assessed in Long-Evans rats 4, 8, 12 and $24 \mathrm{~h}$ and in Fisher 344 rats 4,8 and $12 \mathrm{~h}$ after ozone or air exposure. For each time point and exposure, 8-10 animals were tested. Evans blue dye extravasation was studied in Long-Evans rats $12 \mathrm{~h}$ after a $4 \mathrm{~h}$ exposure to ozone or air ( $\mathrm{n}=8$ per group).

\section{Methods}

Ozone exposure. Rats were exposed to ozone (0.05 ppm) for $4 \mathrm{~h}$ in an exposure chamber made of Plexiglas ${ }^{\mathrm{TM}}$, measuring $20 \mathrm{~cm} \times 30 \mathrm{~cm} \times 40 \mathrm{~cm}$. Control animals were exposed to room air for $4 \mathrm{~h}$ in the same exposure chamber. At each exposition, three rats were kept in the chamber. Ozone was generated by means of high voltage electrostatic pulses in an Ozomat COM ozone generator (Anseros, Tübingen, Germany) which was connected with Teflon tubing to the inlet of the exposition chamber. Ozone concentrations in the exposition chamber were analysed continuously by a Ozomat MP Ozone Analyser (Anseros) which was calibrated against an Envitec CSI 3100 ozone analyser (SI Columbia Scientific Industries Corp., Lafayette, LA, USA), which in turn was calibrated against a standard ozone source at the "IRCEL Ykbank" in Brussels. Ozone concentrations measured in the exposure chamber varied around $50 \mathrm{ppb}$ (range 40-57).

Lung function measurements and assessment of airway responsiveness. Rats were anaesthesized by an intraperitoneal injection of pentobarbital, in a dose of $60 \mathrm{mg} \cdot \mathrm{kg}$ body weight ${ }^{-1}$; additional pentobarbital was administered if necessary to obtain adequate anaesthesia. A Teflon canula (35 mm length and $1.67 \mathrm{~mm}$ ID) was inserted in the cervical trachea through a tracheostomy and ligated firmly. The femoral artery was cannulated with a polyethylene catheter (polyethylene tubing Intramedic, ID 1.77 $\mathrm{mm}$, outer diameter $2.80 \mathrm{~mm}$; Clay Adams, Parsippany, NJ, USA) to monitor blood pressure and heart rate with a pressure transducer (Statham P23; Gould Medical BV, Bilthoven, the Netherlands). A small polyethylene cath- eter was inserted in the external jugular vein to administer intravenous drugs and fluids.

Animals were placed on a heating pad $\left(37^{\circ} \mathrm{C}\right)$ and were connected to a Palmer small animal respirator (BioScience, Harbor Estate, Sheerness, UK) and ventilated with oxygenenriched air, with a tidal volume of $2-2.5 \mathrm{~mL}$ at a rate of 75 strokes $\cdot \mathrm{min}^{-1}$. The spontaneous respiratory movements were interrupted by the intravenous injection of pancuronium bromide, $0.2 \mathrm{mg} \cdot \mathrm{kg}$ body weight ${ }^{-1}$. The arterial blood gases were measured after $10 \mathrm{~min}$ of ventilation and the stroke volume was adapted if necessary to maintain the values of $\mathrm{pH}$, arterial carbon dioxide tension $\left(\mathrm{Pa}_{\mathrm{a}} \mathrm{CO}_{2}\right)$ and arterial oxygen tension $\left(\mathrm{Pa}_{\mathrm{a}} \mathrm{O}_{2}\right)$ within the normal range $(<6.0 \mathrm{kPa}(<45 \mathrm{mmHg})$ and $>10.6 \mathrm{kPa}(>80 \mathrm{mmHg})$, respectively, $\mathrm{pH}$ 7.35-7.45).

Lung resistance $(R \mathrm{~L})$ was continuously calculated from tidal volume, air flow and transpulmonary pressure (PR 800; Mumed, London, UK). The airflow at the outlet of the intratracheal cannula was measured by a Fleisch pneumotachograph Type 0000 (Fleisch, Geneva, Switzerland). The tidal volume was obtained by integration of the flow (PR 800 ; Mumed). The transpulmonary pressure was measured by a differential pressure transducer (Model LCVR; Celesco Transducer Products Inc., Lanoga Park, CA, USA). One end of the differential pressure transducer was attached to a catheter connected to a side-port of the outlet of the tracheal cannula and the other end was attached to an air-filled catheter inserted into the pleural cavity.

Airway responsiveness to 5-HT (serotonin) was measured by administering increasing doses of 5-HT intravenously (boluses of $0.5,1.0,2.5,5.0,10.0,25.0,50.0$ and $100.0 \mu \mathrm{g} \cdot \mathrm{kg}$ body weight ${ }^{-1}$ ). Between injections, a minimum time interval of $2 \mathrm{~min}$ was respected and airway resistance and blood pressure were allowed to return to baseline value.

Evans blue extravasation. After anaesthesia by intraperitoneal injection with pentobarbital $(60 \mathrm{mg} \cdot \mathrm{kg}$ body weight $^{-1}$ ), Evans blue dye, dissolved in $0.9 \%$ saline at a concentration of $30 \mathrm{mg} \cdot \mathrm{mL}^{-1}$, was, injected into the left external jugular vein $\left(30 \mathrm{mg} \cdot \mathrm{kg}^{-1}\right), 12 \mathrm{~h}$ after the end of the ozone exposure. After $5 \mathrm{~min}$, the chest wall was opened and the thoracic descending aorta and inferior caval vein were ligated. After catheterization of the left ventricle and opening of the left atrium, and flushing with saline for $2 \mathrm{~min}$, the heart, trachea and lungs were excised. After removal of excess fluid by blotting the specimens with absorbing paper, the trachea and main bronchi were weighed separately.

Evans blue dye was extracted from trachea and main bronchi by incubation in $100 \%$ formamide for $16 \mathrm{~h}$ at $37^{\circ} \mathrm{C}$ (main bronchi in $1 \mathrm{~mL}$; trachea in $2 \mathrm{~mL}$ ) and measured by assessment of absorption at $620 \mathrm{~nm}$ (interpolation to standard curve, 195-12,500 ng Evans blue $\mathrm{mL}$ formamide $^{-1}$, Titertek Multiscan MCC spectrophotometer; Flow Laboratories, Brussels, Belgium).

Bronchoalveolar lavage. Immediately after the determination of airway responsiveness, BAL was performed via intratracheal instillation of two washings of $4 \mathrm{~mL}$ saline. The fluid was recovered manually by gentle aspiration with a disposable, pyrogen-free syringe while exercising gentle pressure on the thorax. The lavage fluid was immediately centrifuged $(250 \times g$ for $7 \mathrm{~min}$ at 
$4^{\circ} \mathrm{C}$ ) and the cell pellet was resuspended in $1 \mathrm{~mL}$ phosphate-buffered saline (PBS). The supernatant was again centrifuged $\left(1500 \times g\right.$ for $15 \mathrm{~min}$ at $\left.4^{\circ} \mathrm{C}\right)$ to remove remaining cell debris.

The cells were counted manually in a Bürker chamber. Cytospin preparations (Cytospin II; Shandon, Runcorn, UK; centrifugation $20 \times g$ for $5 \mathrm{~min}$ ) were stained with May-Grünwald-Giemsa and a differential cell count based on standard morphological criteria was performed on 300 cells.

Drugs and chemicals. Pentobarbital (Abbott Laboratories, Louvain-la-Neuve, Belgium), pancuroniumbromide (Organon, Brussels, Belgium), 5-HT and sodium ethylenediaminetetraacetic acid (EDTA; Sigma Chemical Co., St. Louis, MO, USA), Hank's solution (Pasteur, Brussels, Belgium), and saline (Baxter, Lessines, Belgium) were obtained from regular commercial sources. Evans blue dye was purchased from Diagnostica Merck, Darmstadt, Germany.

\section{Statistical analysis}

Reported values are expressed as mean \pm SEM. For measurement of bronchial responsiveness, cumulative doseresponse curves for changes in $R \mathrm{~L}$ with increasing doses of 5 -HT were constructed. The changes in $R \mathrm{~L}$ are expressed as the percentage increase in lung resistance. The cumulative dose-response curves were compared by a multiple-way analysis of variance (ANOVA), testing for the main effects of bronchoconstrictor dose and presence or absence of exposure to ozone, on the magnitude of bronchoconstriction, expressed as the percentage increase of airway resistance to the baseline value. Other outcome variables were compared using a Student's t-test, if the values were normally distributed or a Mann-Whitney U-test for nonnormally distributed values. To find out if data sets were normally or non-normally distributed, a Shapiro-Wilk's test was performed. In all statistical tests, p-values of $<0.05$ were regarded as significant. For the statistical analysis, the SPSS program was used (SPSS Inc., Chicago, IL, USA).

\section{Results}

Figure 1 illustrates the effect of exposure to a low concentration of ozone on bronchoconstrictor dose-response curves to 5-HT. In Long-Evans rats, Lewis rats and BDII rats, ozone induced a leftward shift (ANOVA $\mathrm{p}<0.05$ ) of the dose-response curve compared to control animals. Moreover, a nonsignificant enhancement of the maximal bronchoconstrictor response by ozone exposure was observed in Long-Evans (Mann-Whitney U-test, $\mathrm{p}=0.07$ ) and Lewis rats (Student's t-test, $\mathrm{p}=0.06$ ). In Wistar, Sprague-Dawley, Fisher 344, Brown-Norway, BDE and DA rats, exposure to ozone did not change the airway responsiveness to 5-HT (data for Wistar, BDE and DA rats not shown). The total number of cells, the number of neutrophils, mononuclear cells or lymphocytes in BAL fluid, obtained $2 \mathrm{~h}$ after the end of the exposure, were not significantly different in ozone-exposed versus control animals in any rat strain (data not shown).
Figure 2 shows the cumulative dose-response curve to 5-HT in Long-Evans rats at 4, 8, 12 and $24 \mathrm{~h}$, and in Fisher 344 rats at 4,8 and $12 \mathrm{~h}$ after the end of exposure to ozone or room air. The dose-response curves of the ozone-exposed Long-Evans rats obtained at $8 \mathrm{~h}$ and $12 \mathrm{~h}$, but not at $4 \mathrm{~h}$ or $24 \mathrm{~h}$ showed a significant leftward shift compared with those of control animals (ANOVA, $\mathrm{p}<$ $0.05)$. A significant increase in the maximal bronchoconstrictor response to the highest dose of 5-HT was observed in the dose-response curve of $12 \mathrm{~h}(\mathrm{p}<0.05)$. In Fisher 344 rats, no airway hyperresponsiveness was observed at any time-point after ozone exposure.

Total leukocyte count, neutrophil, mononuclear or lymphocyte counts in the BAL fluid was at significantly different between ozone-exposed and control animals of both rat strains at any time-point. Moreover, there was no significant increase in lactate dehydrogenase, alkaline phosphatase, urea or total protein content in BAL fluid supernatant of ozone-exposed animals (table 1). In Long-Evans rats exposed to ozone or air, no significant differences were observed in extravasation of Evans blue dye in trachea (54.25 \pm 35.24 and $15.42 \pm 4.76 \mathrm{mg}$ Evans Blue dye $\mathrm{mg}$ (wet weight) tissue $\mathrm{e}^{-1}$, respectively; $\mathrm{p}=0.06$ ) or main bronchi $(74.76 \pm 26.73$ and $38.51 \pm 6.08 \mathrm{mg}$ Evans Blue dye $\cdot \mathrm{mg}$ (wet weight) tissue ${ }^{-1}$, respectively; $p=0.23$ ), assessed $12 \mathrm{~h}$ after exposure.

\section{Discussion}

In this study, it was observed that a single, short-lasting exposure to a low dose of ozone ( $50 \mathrm{ppb}$ for $4 \mathrm{~h}$ ) induced airway hyperresponsiveness in several, but not all inbred rat strains tested. This hyperresponsiveness developed early, i.e. $90 \mathrm{~min}$ after the end of the ozone exposure and was not accompanied by a neutrophilic inflammation in the airways. This study is the first one to document toxic effects of ambient ozone concentrations in various rat strains. Three out of nine strains developed airway hyperresponsiveness. All strains, with the exception of Wistar rats, consisted of highly inbred animals; the rats were all of similar age and weight. Exposure to ozone and assessment of airway responsiveness in different strains took place at the same time of the day, which excludes diurnal factors as a source of the observed inter-strain variation. Since ozone exposure levels and environmental conditions were the same for all strains, intrinsic, i.e. genetic, factors are likely to account for the apparent differences in sensitivity to ozone.

Previous studies in the authors' laboratory have demonstrated that genetic factors control airway responsiveness to direct and indirect stimuli in rats. Significant differences between inbred rat strains with regard to airway responsiveness to 5-HT (which is the main bronchoconstrictor mast cell mediator in the rat [6]) have been observed and breeding experiments have demonstrated that the airway responsiveness to 5-HT is inherited with a pattern that fits with an autosomal recessive type of inheritance [7]. In the present experiment, however, there was no correlation of baseline responsiveness to 5-HT with the presence or absence of ozone-induced airway hyperresponsiveness.

Differential susceptibility to the induction of airway hyperresponsiveness and airway inflammation by high levels of ozone ( $2 \mathrm{ppm}$ for $3 \mathrm{~h}$ ) was observed in mice. As in the 
a)

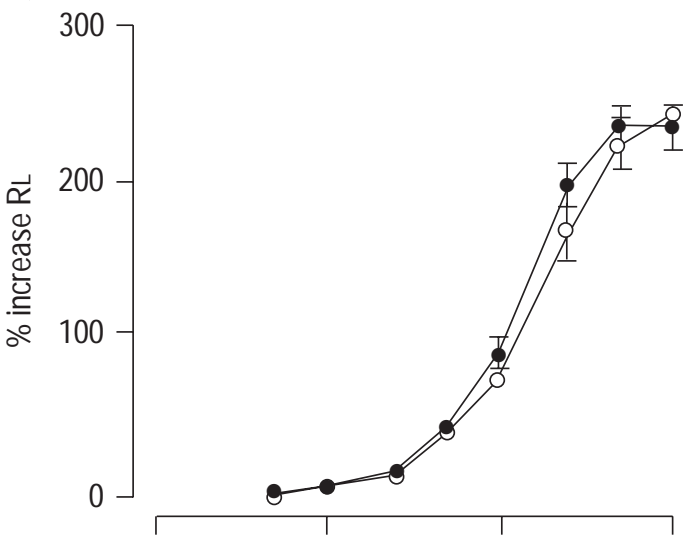

c)

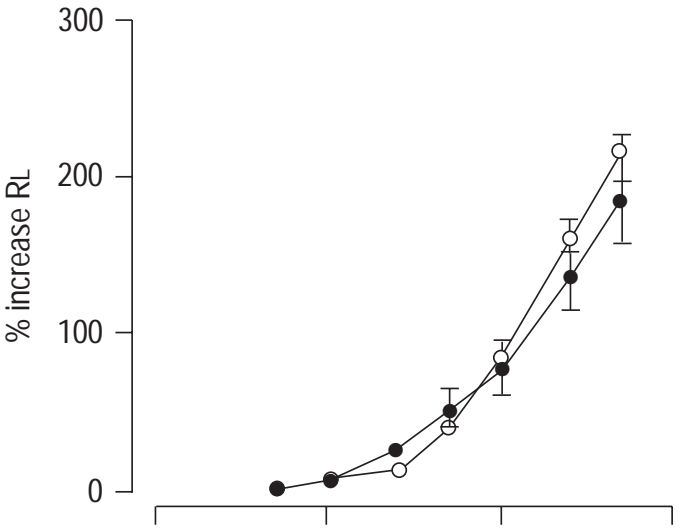

e)

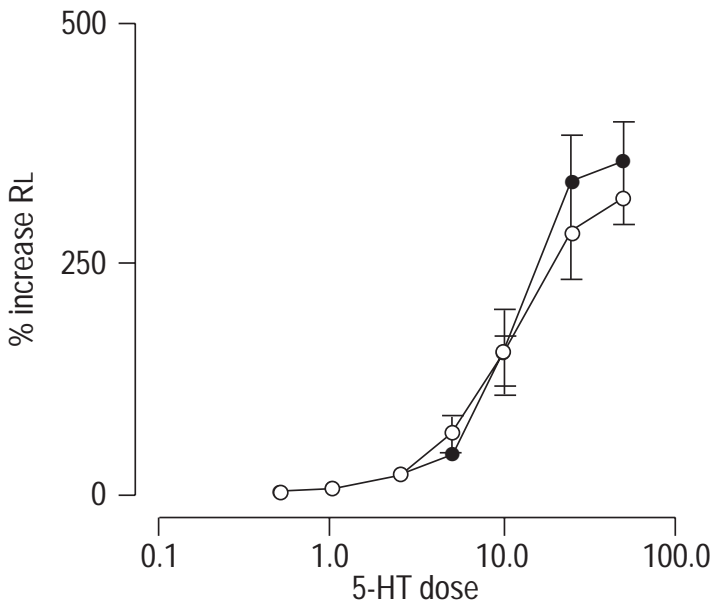

b)

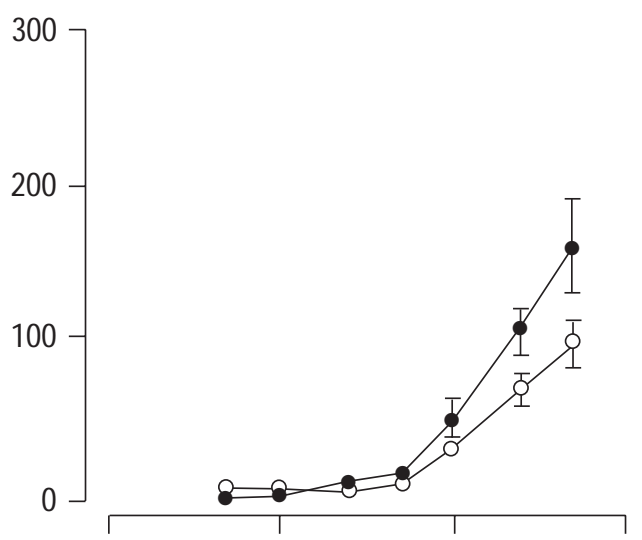

d)

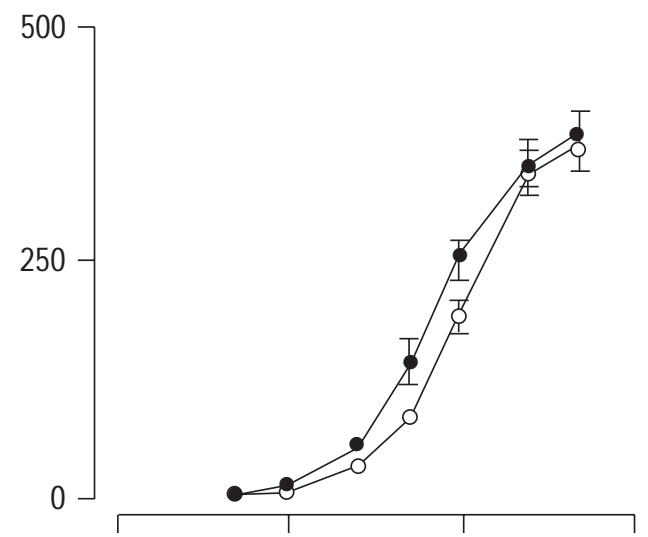

f)

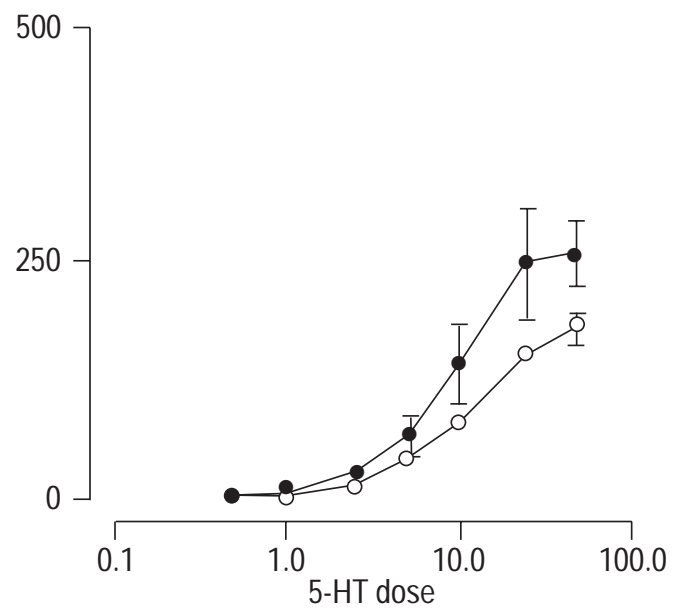

Fig. 1. - Effect of a 4 h exposure to 0.05 parts per million $(\mathrm{ppm})$ ozone $(\bullet)$ on airway responsiveness to 5-hydroxytryptamine (HT) in highly inbred rat strains a) Fisher 344, b) Long-Evans, c) Brown-Norway, d) BD II, e) Sprague-Dawley, and f) Lewis (n=10 per strain and exposure). Exposure to room air was used as the control $(\mathrm{O})$. Data presented as mean \pm SEM. $R$ L: Lung resistance. For $\mathrm{b}, \mathrm{d}$ and $\mathrm{f}$ there was a significant shift in dose-response curves $(\mathrm{p}<0.05)$.

present study, the induction of airway hyperresponsiveness by ozone was not correlated with baseline airway responsiveness [8]. A large interindividual variation in the presence and degree of ozone-induced lung function decrements and airway inflammation [9], as well as airway hyperresponsiveness [10] has also been described in humans, even among homogeneous, healthy study populations. Currently, no parameters reliably predict which individuals are more sensitive to the effects of ozone. Asth- matics in particular have not consistently been shown to be more prone to ozone-induced lung function decrements than healthy control subjects [11-14].

An important observation in the present study is that airway hyperresponsiveness could be induced by a single, short exposure to a low concentration of ozone, which is even below the current upper limit of the National Ambient Air Quality Standards [15]. This would suggest that important deleterious respiratory effects can be provoked 

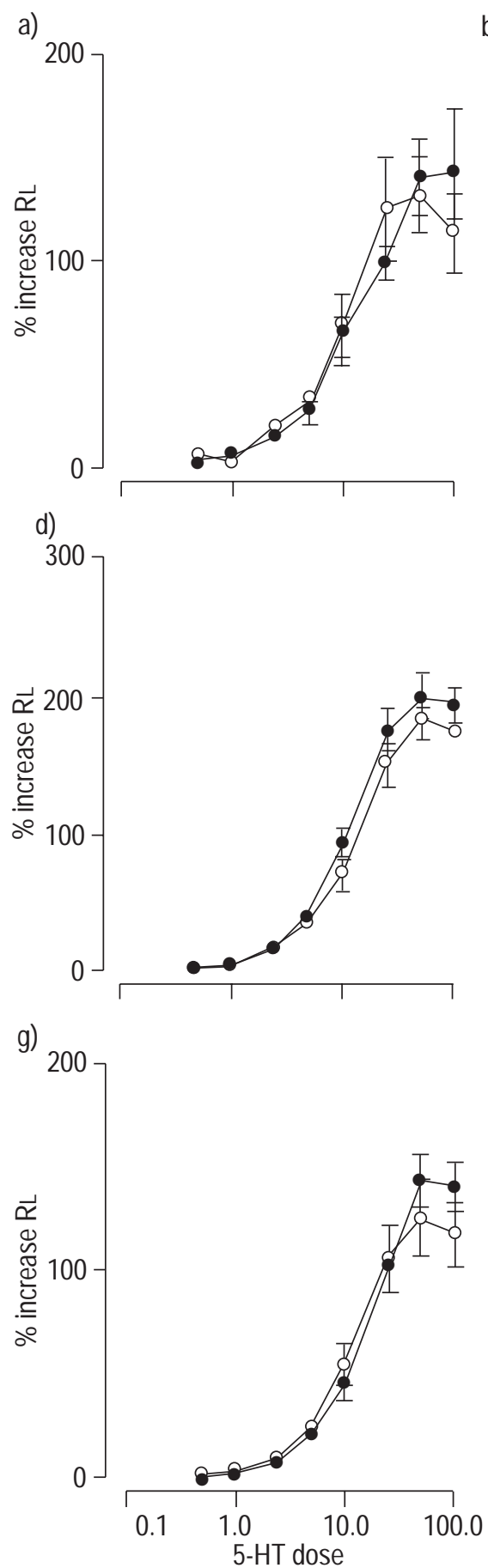

by ozone levels that are frequently reached in large areas of the industrialized world during several months of the year. However, the biological effects that are observed in these different rats strains may not be easily extrapolated to humans. НАтс et al. [16] suggested that ozone toxicity in Fisher 344 rats might underestimate the effects in exercising humans, because in rats a lower dose of ozone reaches the distal lung. As yet, all experimental animal research about the toxicity of ozone has used ozone levels that far exceed ambient concentrations. The present study shows that it can be appropriate in animal studies to focus on more realistic ozone concentrations.
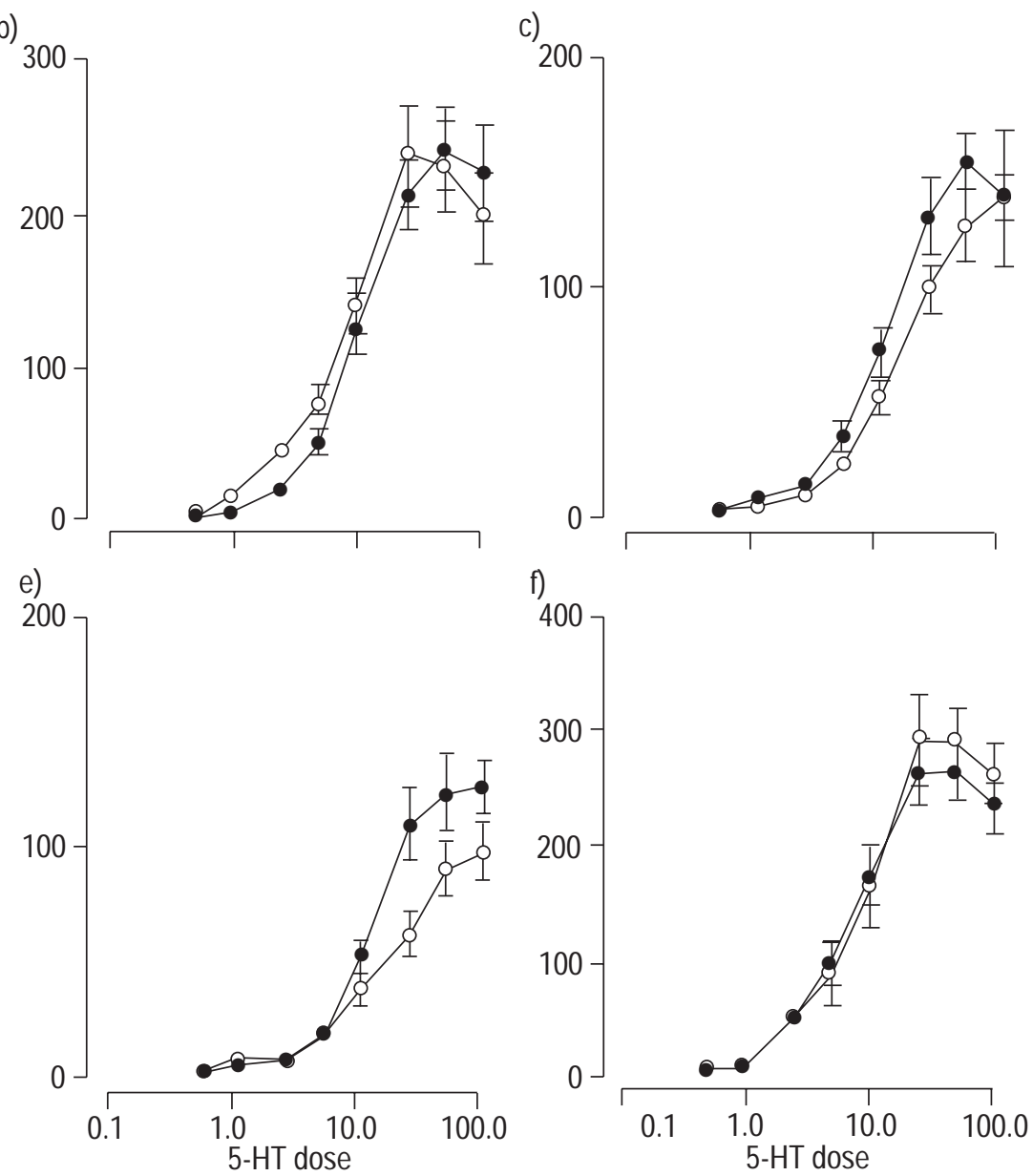

Fig. 2. - Time course of the airway responsiveness to 5hydroxytryptamine (HT) in Long-Evans (a, c, e, and g) and Fisher $344(\mathrm{~b}, \mathrm{~d}$, and f) rats after a $4 \mathrm{~h}$ exposure to 0.05 parts per million $(\mathrm{ppm})$ ozone $(\bullet)$ or room air $(\bigcirc)$. Measurement of lung resistance $(R \mathrm{~L})$ was taken at 4 (a and b), 8 (c and $\mathrm{d}), 12$ (e and $\mathrm{f}$ ) and $24 \mathrm{~h}(\mathrm{~g})$ after the end of exposure $(n=8-10$ per time point and per exposure). Data presented as mean \pm SEM. For $\mathrm{c}$ and e there was a significant shift in the dose-response curves $(\mathrm{p}<0.05)$.
These data confirm that airway hyperresponsiveness occurs rapidly after exposure to ozone, i.e. $90 \mathrm{~min}$ after a single $4 \mathrm{~h}$ exposure. Similarly, in human subjects, bronchial hyperresponsiveness has been observed in the first hours [17-19] or even immediately after [20] a short exposure to ozone. The present study protocol did not allow the exclusion of the possibility that some rat strains which did not become hyperresponsive at the moment of study, would still develop airway hyperresponsiveness at later time points. However, at least in Fisher 344 rats, no airway hyperresponsiveness was present up to $12 \mathrm{~h}$ after exposure. 
Table 1. - Total protein, lactate dehydrogenase and alkaline phosphatase in bronchoalveolar lavage fluid supernatant of Long-Evans rats, 4, 8, 12 and $24 \mathrm{~h}$ after exposure to ozone or room air

\begin{tabular}{|c|c|c|c|c|c|c|}
\hline \multirow{2}{*}{$\begin{array}{l}\text { Time after } \\
\text { exposure } \\
\text { h }\end{array}$} & \multicolumn{2}{|c|}{$\begin{array}{l}\text { Total protein } \\
\mathrm{mg} \cdot \mathrm{dL}^{-1}\end{array}$} & \multicolumn{2}{|c|}{$\begin{array}{c}\text { Lactate dehydrogenase } \\
\mathrm{U} \cdot \mathrm{L}^{-1}\end{array}$} & \multicolumn{2}{|c|}{$\begin{array}{c}\text { Alkaline phosphatase } \\
U \cdot L^{-1}\end{array}$} \\
\hline & Ozone & Control & Ozone & Control & Ozone & Control \\
\hline 4 & $50.2 \pm 7.1$ & $57.6 \pm 8.1$ & $94.8 \pm 10.0$ & $72.9 \pm 5.8$ & $51.8 \pm 3.7$ & $47.8 \pm 3.5$ \\
\hline 8 & $46.5 \pm 7.5$ & $65.8 \pm 9.0$ & $93.6 \pm 7.8$ & $94.3 \pm 8.9$ & $47.4 \pm 5.1$ & $48.0 \pm 4.9$ \\
\hline 12 & $47.0 \pm 8.4$ & $46.1 \pm 5.4$ & $79.2 \pm 3.8$ & $85.8 \pm 11.9$ & $55.2 \pm 6.2$ & $51.4 \pm 6.2$ \\
\hline 24 & $45.3 \pm 3.8$ & $50.7 \pm 8.8$ & $76.4 \pm 4.8$ & $81.8 \pm 4.3$ & $66.4 \pm 3.4$ & $59.6 \pm 7.1$ \\
\hline
\end{tabular}

Results are expressed as mean \pm SEM.

No inflammatory cell influx was observed in BAL fluid or lung histology (data not shown) in any rat strain $90 \mathrm{~min}$ after ozone exposure. In the hyperresponsive Long-Evans rats, no inflammation occurred in the first $24 \mathrm{~h}$. Vascular permeability, as assessed at $12 \mathrm{~h}$ by Evans blue extravasation, and at various time-points by BAL fluid total protein content, the most sensitive marker of ozoneinduced inflammation [21] was not significantly different between ozone-exposed and control animals. A similar observation was made by Evans et al. [22], who noted absence of neutrophilic inflammation or increased tracheal vascular permeability despite airway hyperresponsiveness in Long-Evans rats after much higher ozone concentrations ( $4 \mathrm{ppm}$ for $2 \mathrm{~h}$ ). In contrast, ZHANG et al. [8] found neutrophilic airway inflammation in all mice strains exposed to $2 \mathrm{ppm}$ ozone. Again differences between species and applied ozone levels may be responsible for this apparent discrepancy.

As it has been previously shown that ozone-induced airway hyperresponsiveness and airway inflammation in various animal models are not causally linked $[2,8,23-$ $25]$, the present study also confirms that ozone-induced airway hyperresponsiveness can still occur in total absence of neutrophilic airway inflammation. Hence, it may be that increased airway responsiveness is a more sensitive marker of ozone toxicity. It appears that the threshold of the dose of ozone necessary to provoke airway hyperresponsiveness is lower than the threshold for inducing airway inflammation. Alternatively, the airway hyperresponsiveness occurring after exposure to a low level of ozone may be mediated through different mechanisms than the hyperresponsiveness observed after high concentrations of ozone. Further study is clearly needed to address this issue.

Dissociation between ozone-induced lung function decrements, bronchial hyperresponsiveness and airway inflammation has also been documented in humans. People who develop the largest lung function changes are not necessarily those with the most pronounced neutrophilic inflammation [9, 26-28].

In conclusion, a single, short-lasting exposure to an ambient level of ozone induced airway hyperresponsiveness in several inbred rat strains. Airway hyperresponsiveness was induced despite the absence of a demonstrable airway inflammation. This study adds further to the concern about the toxicity of low levels of ozone and underscores the dissociation of ozone-induced airway hyperresponsiveness and inflammation. It also suggests the influence of genetic factors on the airway response to ozone.
Acknowledgements. The authors gratefully acknowledge the excellent technical assistance of G. Van der Reysen, E. Castrique and C. Snauwaert for help with the technical aspects of the ozone exposure.

\section{References}

1. Bascom R, Bromberg PA, Costa DA, et al. Committee of the Environmental and Occupational Health Assembly of the American Thoracic Society: health effects of outdoor air pollution. Am J Respir Crit Care Med 1996; 153: 3-50.

2. Chitano P, Hosselet JJ, Mapp CE, Fabbri LM. Effect of oxidant air pollutants on the respiratory system: insights from experimental animal research. Eur Respir J 1995; 8: 1357-1371.

3. Juniper EF, Frith PA, Hargreave FE. Airway responsiveness to histamine and methacholine: relationship to minimum treatment to control symptoms of asthma. Thorax 1981; 36: 575-579.

4. Pino MV, Levin JR, Stovall MY, Hyde DM. Pulmonary inflammation and epithelial injury in response to acute ozone exposure in the rat. Toxicol Appl Pharmacol 1992; 112: 64-72.

5. Pauwels RA, Joos GF, Kips JC. Animal models for studying genetics of asthma. In: Barnes PJ, Grunstein MM, Leff AR, Woolcock AJ, eds. Asthma. Philadelphia, Lippincott-Raven, 1997; pp. 275-279.

6. Church MK. Response of rat lung to humoral mediators of anaphylaxis and its modification by drugs and sensitization. Br J Pharmacol 1975; 55: 423-430.

7. Pauwels R, Van Der Straeten M, Weyne J, Bazin H. Genetic factors in non-specific bronchial reactivity in rats. Eur J Respir Dis 1985; 66: 98-104.

8. Zhang LY, Levitt RC, Kleeberger SR. Differential susceptibility to ozone-induced airways hyperreactivity in inbred strains of mice. Exp Lung Res 1995; 21: 503-518.

9. Kulle TJ, Saunder LR, Hebel JR, Chatham MD. Ozone response relationships in healthy nonsmokers. Am Rev Respir Dis 1985; 132: 36-41.

10. Horstman DH, Folinsbee LJ, Ives PJ, Abdul-Salaam S, McDonnell WF. Ozone concentration and pulmonary response relationships for 6.6-hour exposures with five hours of moderate exercise to $0.08,0.10$ and $0.12 \mathrm{ppm}$. Am Rev Respir Dis 1990; 142: 1158-1163.

11. Linn WS, Buckley RD, Spier CE, et al. Health effects of ozone exposure in asthmatics. Am Rev Respir Dis 1978; 117: 835-843.

12. Koenig JQ, Covert DS, Marshall SG, Van Belle G, Pierson WE. The effects of ozone and nitrogen dioxide on pulmonary function in healthy and in asthmatic adolescents. Am Rev Respir Dis 1987; 136: 1152-1157.

13. Horstman DH, Ball BA, Brown J, Gerrity T, Folinsbee LJ. 
Comparison of pulmonary responses of asthmatic and nonasthmatic subjects performing light exercise while exposed to a low level of ozone. Toxicol Ind Health 1995; 11: 369-385.

14. Scannell C, Chen L, Aris RM, et al. Greater ozoneinduced inflammatory responses in subjects with asthma. Am J Respir Crit Care Med 1996; 154: 24-29.

15. U.S. Environmental Protection Agency. National Air Quality and Emissions Trends Report. Office of Air Quality Planning and Standards, Research Triangle Park, NC. 450-R-92-001, 1991.

16. Hatch GE, Slade R, Harris KP, et al. Ozone dose and effect in humans and rats. Am J Respir Crit Care Med 1994; 150: 676-683.

17. Holtzman MJ, Cunningham JH, Sheller JR, Irsigler GB, Nadel JA, Boushey HA. Effect of ozone on bronchial reactivity in atopic and nonatopic subjects. Am Rev Respir Dis 1979; 120: 1059-1067.

18. Seltzer J, Bigby BG, Stulbarg $\mathrm{M}$, et al. $\mathrm{O}_{3}$-induced change in bronchial reactivity to methacholine and airway inflammation in humans. $J$ Appl Physiol 1986; 60: 13211326.

19. Kreit JW, Gross KB, Moore TB, Lorenzen TJ, D'Arcy J, Eschenbacher WL. Ozone-induced changes in pulmonary function and bronchial responsiveness in asthmatics. $J$ Appl Physiol 1989; 66: 217-222.

20. Golden JA, Nadel JA, Boushey HA. Bronchial hyperirritability in healthy subjects after exposure to ozone. $\mathrm{Am}$ Rev Respir Dis 1978; 118: 287-293.

21. Guth DJ, Warren DL, Last JA. Comparative sensitivity of measurements of lung damage made by bronchoalveolar lavage after short-term exposure of rats to ozone. Toxicology 1986; 40: 131-143.

22. Evans TW, Brokaw JJ, Chung KF, Nadel JA, McDonald DM. Ozone-induced bronchial hyperresponsiveness in the rat is not accompanied by neutrophil influx or increased vascular permeability in the trachea. Am Rev Respir Dis 1988; 138: 140-144.

23. Tsukagoshi H, Haddad EB, Sun J, Barnes P, Chung KF. Ozone-induced airway hyperresponsiveness: role of superoxide anions, NEP, and BK receptors. J Appl Physiol 1995; 78: 1015-1022.

24. Koto H, Salmon M, Haddad EB, Huang TJ, Zagorski J, Chung KF. Role of cytokine-induced neutrophil chemoattractant (CINC) in ozone-induced airway inflammation and hyperresponsiveness. Am J Respir Crit Care Med 1997; 156: 234-239.

25. Li Z, Daniel EE, Lane CG, Arnaout MA, O'Byrne PM. Effect of an anti-Mo1 Mab on ozone-induced airway inflammation and airway hyperiesponsiveness in dogs. $\mathrm{Am}$ J Physiol 1992; 263: L723-L726.

26. Schelegle ES, Siefkin AD, McDonald RJ. Time course of ozone-induced neutrophilia in normal humans. Am Rev Respir Dis 1991; 143: 1353-1358.

27. Aris RM, Christian D, Hearne PQ, Kerr K, Finkbeiner WE, Balmes JR. Ozone-induced airway inflammation in human subjects as determined by airway lavage and biopsy. Am Rev Respir Dis 1993; 148: 1363-1372.

28. McDonnell W, Koren H, Devlin R, Abdul-Salaam S, Ives $\mathrm{P}, \mathrm{O}^{\prime}$ Neil J. Biochemical and cellular correlates of changes in pulmonary function and symptoms in humans exposed to ozone. Am Rev Respir Dis 1990; 141: A72. 